\title{
Lyso-Thermosensitive Liposome Doxorubicin
}

National Cancer Institute

\section{Source}

National Cancer Institute. Lyso-Thermosensitive Liposome Doxorubicin. NCI Thesaurus. Code C61571.

A temperature-sensitive liposomal formulation of the anthracycline antibiotic doxorubicin with potential antineoplastic activity. Upon intravenous administration, circulating thermosensitive liposomes are activated locally by increasing the tumor temperature to 40-41 degrees Celsius using an external heat source. The elevated temperature causes compositional changes in the liposomes, creating openings that allow for the release of encapsulated doxorubicin. Compared to non-thermosensitive liposomes, lysothermosensitive liposomes deliver higher concentrations of a cytotoxic agent to a heattreated tumor site while sparing normal tissues unexposed to heat treatment. 